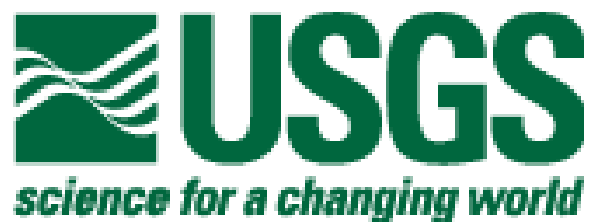

\title{
Geologic map and digital database of the Pinto Mountain 7.5 minute quadrangle, Riverside County, California
}

By Robert E. Powell ${ }^{1}$

Digital preparation by Pamela M. Cossette ${ }^{1}$

Readme, version 1.0

Open-File Report 02-491

Online version 1.0

http://geopubs.wr.usgs.gov/open-file/02-491

2002

U.S. Department of the Interior

U.S. Geological Survey

Prepared in cooperation with

National Park Service

California Geological Survey

A product of the Southern California Areal Mapping Project

${ }^{1}$ U.S. Geological Survey, Western Region Earth Surface Processes Team W904 Riverside Avenue, Spokane, WA 99201-1087

For database limitations, see following page 


\section{DATABASE LIMITATIONS}

\section{Content}

This database is preliminary and has not been reviewed for conformity with U.S. Geological Survey editorial standards or with the North American Stratigraphic Code. Any use of trade, product, or firm names is for descriptive purposes only and does not imply endorsement by the U.S. Government.

This database, identified as " Geologic map and digital database of the Pinto Mountain 7.5 minute quadrangle, Riverside County, California," has been approved for release and publication by the Director of the U.S. Geological Survey. Although this database has been subjected to rigorous review and is substantially complete, the USGS reserves the right to revise the data pursuant to further analysis and review. Furthermore, it is released on the condition that neither the USGS nor the United States Government may be held responsible for any damages resulting from its authorized or unauthorized use.

\section{Spatial Resolution}

Use of this digital geologic map should not violate the spatial resolution of the data. The Pinto Mountain database was developed using digital orthophotograph quarter quadrangles (DOQQs) as a base. DOQQs have a pixel resolution of $1 \mathrm{~m}$ and are accurate to a scale of 1:12,000 ( $1 \mathrm{in}=1,000$ $\mathrm{ft}$ ). Any enlargement beyond 1:12,000 exceeds the spatial resolution of the geologic data and should not be used in lieu of a more detailed site-specific geologic evaluation. Similarly, the digital topographic base map is derived from the U.S. Geological Survey, 1:24,000-scale Pinto Mountain 7.5 minute quadrangle (provisional edition, 1986); any enlargement beyond 1:24,000 exceeds the spatial resolution of the topographic data. Where the geologic data is used in combination with the topographic data, the resolution of the combined output is limited by the lower resolution of the topographic data. Where this database is used in combination with other data of higher resolution, the resolution of the combined output will be limited by the lower resolution of these data. 


\section{Table of contents}

DATABASE LIMITATIONS...........................................................................

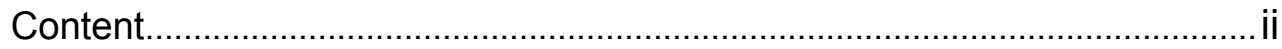

Spatial Resolution .....................................................................................

INTRODUCTION

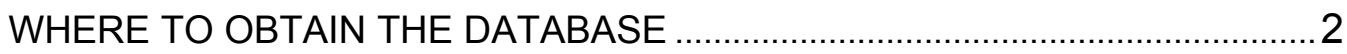

DATABASE INFORMATION AVAILABLE ON THE OPEN-FILE WEBSITE .......3

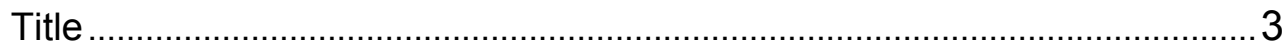

Authors

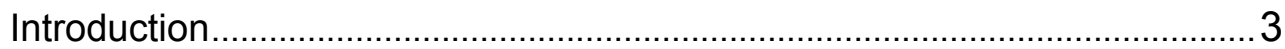

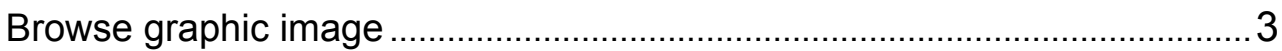

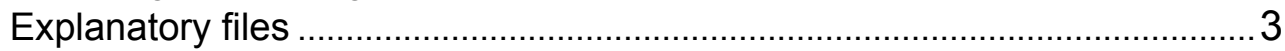

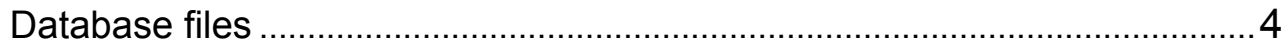

Files for viewing and plotting ...................................................................

HOW TO ACCESS THE DATABASE .............................................................

Extracting the database files .....................................................................

Converting the ARC/INFO interchange/export files ......................................

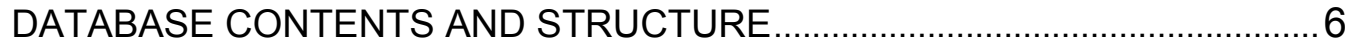

Content

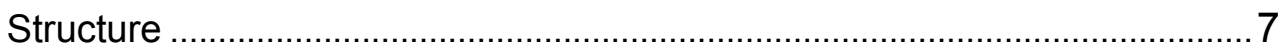

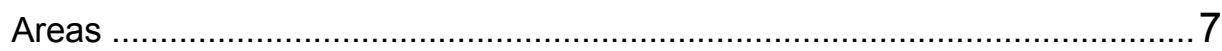

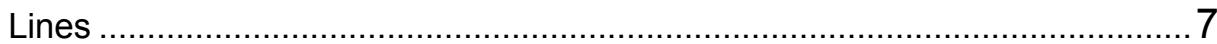

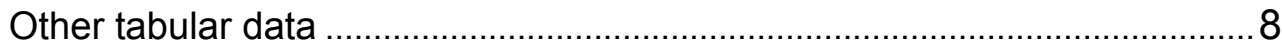

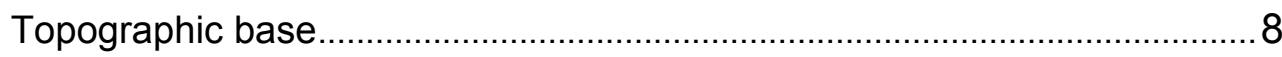

HOW TO OBTAIN A PAPER PLOT OF THE GEOLOGIC MAP ........................ 9

HOW TO ACCESS PORTABLE DOCUMENT FORMAT (.PDF) FILES ..........10

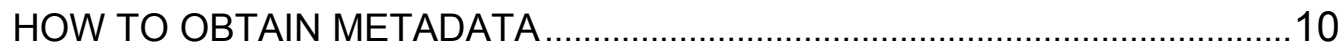

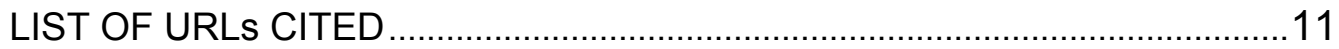

U.S. Geological Survey websites..............................................................11

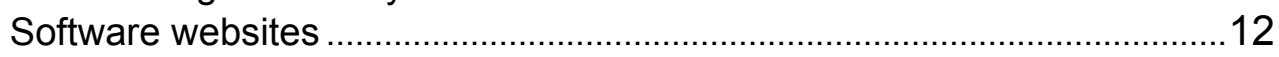




\section{INTRODUCTION}

Open-File Report 02-491 is a digital geologic data set that maps and describes the geology of the Pinto Mountain 7.5-minute quadrangle, Riverside County, southern California. The Pinto Mountain quadrangle lies between $115^{\circ} 45^{\prime}$ and $115^{\circ} 52^{\prime} 30^{\prime \prime}$ west longitude and $34^{\circ}$ and $33^{\circ} 52^{\prime}$ $30^{\prime \prime}$ north latitude. The Pinto Mountain database is one of several quadrangle databases that are in preparation for Joshua Tree National Park and vicinity. These quadrangles are a subset of digital quadrangle maps being generated for the Southern California Areal Mapping Project (SCAMP). The SCAMP maps are, in turn, part of the nation-wide digital geologic map coverage being developed by the National Cooperative Geologic Map Project (NCGMP) of the U.S. Geological Survey (USGS).

The Pinto Mountain data set consists of a digital geologic map database accompanied by graphics, plot, and explanatory files. The digital database was created using ARCVIEW, version 3.2, and ARC/INFO, version 8.1, commercial Geographical Information System (GIS) software designed by Environmental Systems Research Institute (ESRI), Redlands, California (http://www.esri.com). The database includes ARC/INFO geospatial coverages, a scanned 1:24,000-scale topographic base, and supporting SCAMP symbolsets. PostScript and Portable Document Format files contain a geologic map generated from the database combined with map margin explanatory information created in Adobe Illustrator. Other PDF and ASCII text files contain metadata, a readme document, and an explanatory pamphlet. As yet, some, but not all, of the detailed information about geologic units contained in the map-margin explanation has been entered into the digital database. 


\section{WHERE TO OBTAIN THE DATABASE}

The Pinto Mountain 7.5-minute quadrangle data set is available on the USGS Western Region Geologic Publications Server. The data set may be downloaded from the website

http://geopubs.wr.usgs.gov/open-file/01-491

The Pinto Mountain geologic map and database can also be accessed through links to the Western Region Geologic Publication Server by any of the following paths:

- http://geology.wr.usgs.gov/wgmt/scamp/scamp.html

This website provides links to SCAMP-related digital geologic mapping in southern California. The site lists new releases by year and title

- http://geopubs.wr.usgs.gov/

This website provides links to USGS Western Region digital geologic maps, including Open-File. The site lists new releases series and number

- http://pubs.usgs.gov/products/books/openfile//index.html

This website provides links to all digital USGS Open-File Reports by year of publication. The site lists the Open-File Reports by number along with the title of the report

- $\quad$ http://geo-nsdi.er.usgs.gov/cgi-bin/publication/open-file

This website provides links to all digital USGS Open-File Report maps via their metadata files. The site lists the Open-File Reports by number along with the title of the report (see 'How to obtain metadata' below) 


\section{DATABASE INFORMATION AVAILABLE ON USGS GEOPUBS SERVER}

On the USGS Western Region Geologic Publications Server (geopubs) website for the Pinto Mountain geologic map and digital database, information is arranged as follows:

Title

Geologic map and digital database of the Pinto Mountain 7.5-minute quadrangle, Riverside County, southern California

Authors

Robert E. Powell

Pamela M. Cossette (digital cartography)

Introduction

Browse-graphic image

Page-sized, non-navigable image of geologic map with marginal explanation

(pmtn_browse.jpg: 35 KB JPEG image of geologic map with marginal explanation)

Explanatory files

- Readme tabulates contents of database and describes how to access them. Provided on website in ASCII text and Portable Document formats

- Metadata file contains detailed technical descriptions of structure and content of digital data. Provided on website as parseable text in ASCII format, and as outline in Hypertext Markup Language format. Also available on the USGS Geologic Division Node of the National Geospatial Data Clearinghouse in these two and other formats (see 'How to obtain metadata' below).

- Explanatory pamphlet describes approach used in building database, and provides a summary of the geologic framework of the Pinto Mountain quadrangle. Provided on website in Portable Document format

File name

File type and description

$\begin{array}{ll}\text { pmtn_readme.txt } & \text { ASCII readme file } \\ \text { pmtn_readme.pdf } & \text { PDF readme file } \\ \text { pmtn_pamph.pdf } & \text { PDF version of explanatory pamphlet } \\ \text { pmtn_met.txt } & \text { ASCII metadata file }\end{array}$




\section{Database files}

Database files are packaged as a tarred and gzipped file that bundles and compresses the following information:

- Database files: ASCII-formatted ARC/INFO interchange/export (.e00) file for each ARC/INFO coverage, symbolset, and data table. (See 'Database contents and structure' below)

- Topographic base map as a GEOTIFF file

- ASCII text files for readme and metadata

$\begin{array}{lll}\text { File name } & \begin{array}{l}\text { File type and description } \\ =========\end{array} & \text { File size } \\ \text { pmtn.tar.gz } & \begin{array}{l}\text { GZIP compressed } \sim 25-\mathrm{MB} \text { TAR } \\ \text { bundle of all database files }\end{array} & \sim 5 \mathrm{MB}\end{array}$

Files for viewing and plotting

- Gzip-compressed PostScript plot-file for generating paper copy of geologic map with marginal explanation

- Portable Document Format file containing full-sized, navigable graphic image of geologic map with marginal explanation

File name

pmtn_map.ps.gz

pmtn_map.pdf
File type and description

Gzipped 246-MB PostScript plot file of map

with marginal explanation

PDF file containing geologic map

with marginal explanation
File size

$\sim 9 \mathrm{MB}$

$\sim 5 \mathrm{MB}$ 


\section{HOW TO ACCESS THE DATABASE}

\section{Extracting the database files}

The Pinto Mountain database files have been bundled and compressed using tar and gzip utilities. Before attempting to unzip the file after downloading, be sure that the .gz extension is present in the file name.

Extraction creates the directory pmtn/ that contains the database in ARC/INFO interchange (.e00) files, the topographic map in a GEOTIFF file, and the readme, metadata, and explanatory pamphlet in ASCII text files. The database interchange files include eight ARC/INFO coverages and supporting symbolsets and data tables.

Tar and uncompress utilities are included in most UNIX systems, and are available free of charge for all systems at various websites:

Gnu Software: http://www.gnu.org/order/ftp.html (UNIX tar and gzip)

(This web page links to mirror archive sites for Gnu tar and gzip utilities)

Gnu zip: http://www.gzip.org (UNIX gzip)

CNET Shareware: http://shareware.cnet.com/ (Macintosh and Windows) (Search for 'tar' or 'gzip' for any Macintosh or Windows operating system.)

WinZip: http://www.winzip.com (Windows gzip)

USGS Public Domain Software web page:

http://edcwww.cr.usgs.gov/doc/edchome/ndcdb/public.html (UNIX and Macintosh)

(Provides links to Washington University at St. Louis Gnu archive for UNIX tar and gzip; and to AOL mirror site for Macintosh tar and gzip)

Internet Literacy's Common Internet File Formats: http://www.matisse.net/files/formats.html (Macintosh and Windows tar and gzip) (Note: this website has not been maintained since December 1995)

\section{Converting the ARC/INFO interchange/export files}

The ARC interchange/export (.e00) files are converted to ARC coverages using the ARC command IMPORT.

1. Change directories to the $\mathrm{pmtn} /$ directory

2. At the UNIX command prompt, launch ARC/INFO by typing "arc"

3. From the ARC command line type:

import $<$ option $><$ interchange_file $><$ output $>$

(e.g., import auto pmtn_geo pmtn_geo; repeat for each interchange file)

Consult the ARC/INFO command references manual in ESRI's software documentation for other $<$ option $>$ choices appropriate for importing the interchange files. 


\section{DATABASE CONTENTS AND STRUCTURE}

This readme section contains a brief overview of the structure and content of the database. Refer to the metadata for a complete technical description of the database structure and content; refer to the explanatory pamphlet for a discussion of the approach used in building the database and for further discussion of the contents of the various coverages within the database.

\section{Content}

After importing the Pinto Mountain ARC/INFO interchange files, the pmtn/ directory contains eight map coverages, a topographic base-map file, six data tables, four symbolsets, and two documentation (.txt) files:

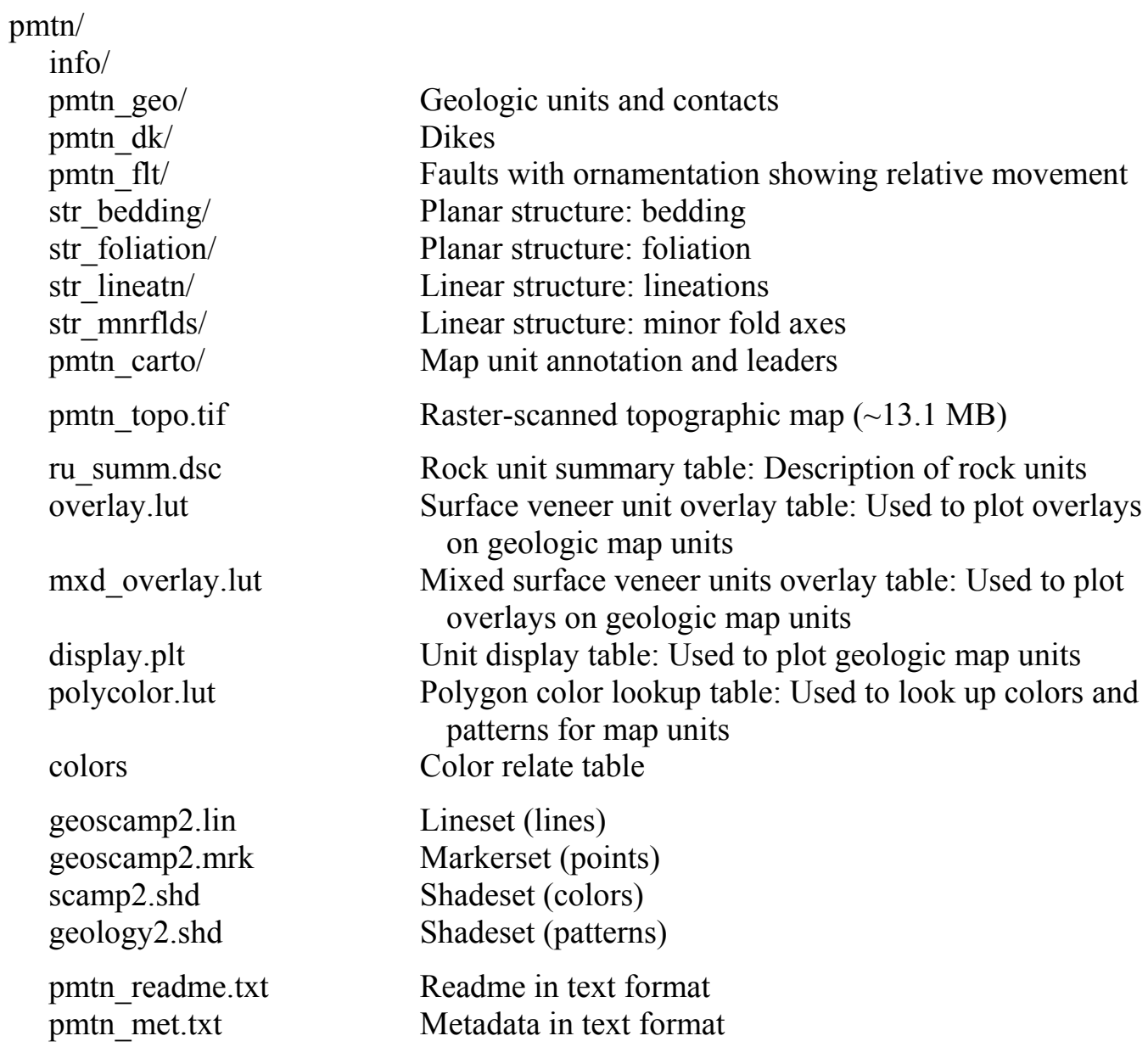

ARC/INFO interchange files can be read by some other Geographic Information Systems, including ARCVIEW (ESRI) and MapInfo (via ArcLink). Please consult your GIS documentation to see if your system recognizes ARC interchange files and follow the procedure to import them. (NOTE: the graphical symbols contained in the two symbolsets (geoscamp2.lin; geoscamp2.mrk) cannot be read directly in ARCVIEW.) 


\section{Structure}

\section{Geospatial features}

The ARC/INFO coverages listed in the previous section constitute the geospatial database. In mapping real-world geologic features into the coverages, ARC/INFO records the spatial coordinates and topology of each feature and stores them in polygon, arc, or point attribute tables (.pat, .aat, and .pat, respectively). In the coverages, polygons and regions (groups of polygons) represent areal geologic features, including rock units, stratigraphic parents of rock units, and landforms. Similarly, arcs and routes (groups of arcs) describe linear geologic features, including contacts, facies boundaries, faults, dikes, and scarps. (In version 1.0, routes have been established for faults only.) Site-specific structural data are represented as points.

Areas. In the Pinto Mountain geologic database, polygons are used to represent areas where geologic and (or) geomorphic units crop out at the Earth's surface. As such, polygons represent areas that are underlain by domains of earth materials that share lithologic or landform characteristics and that are bounded by geologic contacts (including faults where they separate different units), by geomorphic boundaries, and by the map boundary. Polygons tabulated in the attribute table pmtn_geo.pat are tagged with labels of as many units as deemed appropriate to characterize the earth materials represented by the polygon.

The various polygon labels are grouped into rock (map) units and represented as region features. Rock units are represented as regions by grouping related polygons in three ways: (1) to associate sets of non-contiguous polygons that make up a single rock unit; (2) to display hierarchical groupings (e.g., rock unit assemblage units or parent rock units in the stratigraphic hierarchy); and (3) to represent geographic features that overlap other geographic features of the same class (e.g., to represent concealed units as well as units exposed at the surface, to distinguish lithologic and geomorphic units, or to represent lithologic process domains that are overprinted on rock units). Regions are stored as subclasses of the polygon feature class. Each region subclass has its own subclass polygon attribute table that is independent from the polygon attribute table and from the attribute tables of other regions in the same coverage. Thus, more than one region can share the same polygon feature, thereby allowing one to represent more complex relations among polygons than those represented in the polygon attribute table alone.

Using regions, the user can display (in ArcView or ArcMap) different arrays of units and emphasize other aspects of the geology of the quadrangle than those displayed and emphasized in the plot-file map included in this open-file report. For example, the Proterozoic granite gneiss of Joshua Tree (Prjgg) is distinguished from and mapped separately from the porphyritic granite of Joshua Tree (Prjgr), but the gneiss has been shown to be intensely deformed porphyritic granite. In the Pinto Mountain database these units are combined into a parent unit (Prjg) that embraces their shared ancestry. Recognizing that for some uses it may be desirable to generalize the geologic map, we have organized the mapped units into a stratigraphic hierarchy of increasingly generalized parent units that are also attributed as regions in the database. For example, the user may choose to display young alluvial deposits (Qya) and very young alluvial deposits (Qvya) as a combined unit (Qvyya) that includes all Holocene alluvial deposits. Similarly, it may be desirable to represent the various mapped lithosomes of Proterozoic gneiss simply as Pinto Gneiss (Prpg), or to represent the various mapped lithosomes of quartzite simply as the quartzite of Pinto Mountain (Prpq). This capability is particularly useful in incorporating the coverages into smaller-scale databases.

Lines. In the Pinto Mountain coverages, lines include the map boundary, geologic contacts, faults, geomorphic boundaries, linear geologic units (dikes), and leaders for map-unit annotation labels. These lines are tabulated in arc attribute tables. In version 1.0 of the Pinto Mountain coverage library, routes are used to group and further define fault features. Information about faults is entered into the database in two types of routes: fault segments and faults. 
The segments route subclass characterizes fault segments (groups of arcs) that have geological significance. It is used, for example, to distinguish segments of a fault that break alluvium or that are brecciated or that have differing separations, such as the bounding segments of a fault horse.

The fault route subclass is used to attribute entire faults or groups of faults. In version 1.0 of the Pinto Mountain database, fault routes are used to distinguish groups of faults by orientation and by named fault zone or fault system. For example, northwest-trending faults are distinguished from east-west trending faults. Similarly, the various groups of fault arcs that constitute named faults zones (Blue Cut, Eagle Mountain, and East Pinto Basin faults) in the left-lateral Pleasant Valley-Pinto Basin fault system are distinguished from one another.

\section{Other tabular data}

The stand-alone INFO tables contain additional data that augment the geospatial coverages and relate to the feature-attribute tables. Some of these tables contain data that further describe and classify the geologic features; others contain data needed to display or plot geologic maps.

\section{Topographic base}

The topographic base map is a 500-dpi raster scan of USGS Pinto Mountain 7.5 minute quadrangle (provisional edition, 1986), registered and rectified to the coverage quadrangle in ARC/INFO and saved as a Georeferenced Tagged Image Format (GEOTIFF) file. 


\section{HOW TO OBTAIN A PAPER PLOT OF THE GEOLOGIC MAP}

1. Download and, using a gzip utility (see 'Extracting the database files' above), uncompress the file pmtn_map.ps.gz. The 246-MB file pmtn_map.ps is a PostScript plot-file of the geologic map and its explanation. The PostScript file will plot a 1:24,000-scale, full-color geologic map of the Pinto Mountain quadrangle on its topographic base and accompanied by a map-margin explanation. The plot has a format similar to the U.S. Geological Survey's Miscellaneous Investigations (MF) map series, and is approximately 34 x 44 inches in size. It has been plotted successfully on Hewlett-Packard large-format plotters, models HP650C, HP755CM, and HP2500C using $36 \times 48$-in paper.

To add a topographic base to the geologic map, the monochromatic raster-scan file (pmtn_topo.tif) and the geologic map coverages were converted to ARC/INFO grids. The grids were then merged to display the topographic and cultural information from the raster scan in gray, with geologic map unit colors filling the intervening areas of the topographic map. The combined map is a digital image in which geologic and topographic lines and points are displayed in their proper geospatial locations, but in which no information other than location is attached to the lines and points.

The marginal explanation includes a Correlation of Map and Database Units diagram, a Description of Map and Database Units, and a key to line and point symbols. The map margin explanation was created in Adobe Illustrator and imported into ARC/INFO to combine it with the geologic map.

The plot files have been prepared using line- and point-symbols and unit colors and patterns located in the following symbolsets:

$\begin{array}{ll}\text { geoscamp2.lin } & \text { Lineset } \\ \text { geoscamp2.mrk } & \text { Markerset } \\ \text { scamp2.shd } & \text { Shadeset } \\ \text { geology2.shd } & \text { Shadeset }\end{array}$

These sets are included in the pmtn.tar.gz data package and are available at the Southern California Areal Mapping Project (SCAMP) website

http://geology.wr.usgs.gov/wgmt/scamp/attrib/attribute.html

In addition, the plot files contain specialized geologic-age fonts of the GeoAge font group, which is accessed through geofont.txt and is available from the USGS at the Western Region website:

http://geology.wr.usgs.gov/ (or http://wrgis.wr.usgs.gov/).

2. Download and plot the $\sim 5$-MB file pmtn_map.pdf, which generates a paper map equal in quality to that of the much larger post-script plot file. Care must be taken to select a page size format that results in 1:24,000-scale map-plot. 


\section{HOW TO ACCESS PORTABLE DOCUMENT FORMAT (.PDF) FILES}

The .pdf files are accessed using Adobe Acrobat Reader software, available free of charge from the Adobe web site (http://www.adobe.com).

\section{HOW TO OBTAIN METADATA}

Metadata for the Pinto Mountain geologic map database are available as part of the National Spatial Data Infrastructure through the USGS Geologic Division Node of the National Geospatial Data Clearinghouse (http://nsdi.usgs.gov/). Within this site, Open-File Reports are located at

http:/geo-nsdi.er.usgs.gov/cgi-bin/publication/open-file

where they are listed by OF number along with the title. Metadata at this node are viewable in five formats (ASCII as parseable text; HTML outline, HTML as answers to questions, XML, and DIF). Metadata for the Pinto Mountain database site at this node is located at

http://geo-nsdi.er.usgs.gov/metadata/open-file/02-491/metadata.faq.html

ASCII text and HTML outline versions of the metadata are also available as stand-alone files at the Pinto Mountain website (http://geopubs.wr.usgs.gov/open-file/01-491) and the ASCII text version is bundled with database files in the tarred and gzipped file. 


\section{LIST OF URLS CITED}

\section{U.S. Geological Survey websites}

Pinto Mountain 7.5 minute quadrangle

Open-File Report: http://geopubs.wr.usgs.gov/open-file/01-491

Metadata: http://geo-nsdi.er.usgs.gov/metadata/open-file/02-491/metadata.faq.html

Southern California Areal Mapping Project (SCAMP) website

GIS attributes: http://geology.wr.usgs.gov/wgmt/scamp/attrib/attribute.html

Databases: http://geology.wr.usgs.gov/wgmt/scamp/

Western Region website

http://geology.wr.usgs.gov/ (or http://wrgis.wr.usgs.gov/)

Western Region Geologic Publication Server

Open-File Reports:

http://geopubs.wr.usgs.gov/open-file/

All digital publications

http://geopubs.wr.usgs.gov/

U.S. Geological Survey website (http://geology.usgs.gov)

Open-File Reports

Digital maps: http://geology.usgs.gov/open-file/maps.html

Metadata: http://geo-nsdi.er.usgs.gov/cgi-bin/publication/open-file

Metadata (USGS Node of the National Geospatial Data Clearinghouse)

http://nsdi.usgs.gov/

National Geologic Map Database

http://ncgmp.usgs.gov/ngmdbproject/standards/

http://geology.usgs.gov/dm/ 


\section{Software websites}

GIS systems

Environmental Systems Research Institute (ESRI): http://www.esri.com

MapInfo: http://www.mapinfo.com

Compression and tar software

Gnu Software: http://www.gnu.org/order/ftp.html (UNIX tar and gzip)

(This web page links to mirror archive sites for Gnu tar and gzip utilities)

Gnu zip: http://www.gzip.org (UNIX gzip)

CNET Shareware: http://shareware.cnet.com/ (Macintosh and Windows)

(Search for 'tar' or 'gzip' for any Macintosh or Windows operating system.)

WinZip: http://www.winzip.com (Windows gzip)

USGS Public Domain Software web page:

http://edcwww.cr.usgs.gov/doc/edchome/ndedb/public.html (UNIX, Macintosh)

(Provides links to Washington University at St. Louis Gnu archive for UNIX

tar and gzip; and to AOL mirror site for Macintosh tar and gzip)

Internet Literacy's Common Internet File Formats:

http://www.matisse.net/files/formats.html (Macintosh and Windows tar and gzip)

(Note: this website has not been maintained since December 1995)

Portable document reader

Adobe web site: http://www.adobe.com 